\title{
PLAY AND INDIGENOUS GAMES OF CHILDREN: A Cultural Heritage of Western Odisha, India
}

\section{Rashmi PRAMANIK; Shreyasi BHATTACHARYA}

Sambalpur University (India) rashmipramanik@yahoo.co.in

Resumen: El estudio del juego a través del tiempo y las culturas ha demostrado consistentemente que se trata de un fenómeno multifacético que se encuentra en todas partes en diversas sociedades humanas. El presente trabajo hace un esfuerzo humilde para explicar cómo los diferentes tipos de juegos tradicionales de niños rurales se enriquecen con el patrimonio cultural de una sociedad y actúan como una fuente de transmisión de conocimiento. También hace un examen crítico del escenario cambiante de los juegos infantiles en la sociedad contemporánea. El estudio se llevó a cabo entre los niños que van a la escuela en las zonas rurales de Western Odisha, donde la población local está siendo arrinconada y Abstract: las formas de entretenimiento occidentales están ganando popularidad.

The study of play through time and across cultures has consistently demonstrated that, it is a multi-faceted phenomenon being ubiquitous among diverse human societies. The present paper makes an humble endeavour to intricate how different types of traditional games of rural children is being enriched with cultural heritage of a society and act as a source of transmission of knowledge. It also makes a critical examination of the changing scenario of children's games in contemporary society. The study has been conducted among the school going children in the rural pockets of Western Odisha where local populace is getting dodged and western forms of entertainment is gaining popularity.

Palabras clave:

Infancia. Juego Tradicional. Patrimonio Cultural. Globalización Children. Play. Traditional Game. Cultural Heritage. Globalization 


\section{Introduction}

Virtually every child, over the world, plays. The drive to play is so intense that children will do so when they have no real toys, when parents do not actively encourage the behavior, and even in the middle of a war zone. In the eyes of a young child, running, pretending and building are fun. Researchers and educators know that these playful activities benefit the development of the whole child across social, cognitive, physical, and emotional domains. Indeed, play is such an instrumental component to healthy child development that the American Academy of Pediatrics (Ginsburg, 2007) issued a white paper on the topic, the National Association for the Education of Young Children (2009) named play as a central component in developmentally appropriate educational practices, and the United Nations High Commission on Human Rights (1989) recognized play as a fundamental right of every child.

Yet, while experts continue to expound a powerful argument for the importance of play in children's lives, the actual time children spend playing continues to decrease. Today, children play eight hours less each week than their counterparts did two decades ago (Elkind, 2008). Under pressure of rising academic standards, play is being replaced by test preparation in kindergartens and grade schools, and parents who aim to give their preschoolers a leg up are led to believe that flashcards and educational "toys" are the path to success. Our society has created a false dichotomy between play and learning.

Play is observed as a natural and spontaneous phenomenon in the lives of children. All children have a 'Right to Play' or in other words it can be said that 'Play is Child's Work'. For babies, free body movements, sounds and responses to adult stimuli are part of their play performances. As children grow older, such performances little by little become more ordered and activity oriented i.e. running, jumping or playing with toys etc. At a later age, while participating in simple games children learn to pursue certain rules allied with them. Besides games, other forms of play contain completing a half told story, singing, creative drama, riddles etc. Children use play to make sense of the world around them. Open-ended, imaginative play allows them to integrate and master their experiences meaningfully. 'Play' always has different connotation for children and adults. Adults while being busy throughout the day, only play for recreation to break their monotony of work whereas children play all the time except when they are sleeping. Hence it can be said, "Play is to a child what work is to an adult". In other words, "Play is child's work."

The definition of play is both complex and contested and has long been the subject of social and academic debate. The increase in structured 'play' sessions and emergence of technology-based play has led to further confusion over the nature and meaning of play (Lester and Russell 2008). What is clear is that play is an innate childhood instinct, that is not only enjoyable but also crucial to the processes of learning and development. Play is varied and flexible and there is no 'right' or 'wrong' way to play; encompassing an endless range of play types, which could be active or subdued, imaginative or exploratory, involve others or carried out alone. An attempt to distil the essence of play is perhaps best expressed through the Playwork Principles that underpin all good playwork practice:

'Play is a process that is freely chosen, personally directed and intrinsically motivated. That is, children and young people determine and control the content and intent of their play, by following their own instincts, ideas and interests, in their own way for their own reasons.'

'All children and young people need to play. The impulse to play is innate. Play is a biological, psychological and social necessity, and is fundamental to the healthy development and wellbeing of individuals and communities.' (Playwork Principles Scrutiny Group 2005)

In other words, play involves children doing as they wish in their own time and in their own way, and it is this component of play that is key to understanding the positive outcomes of playing throughout childhood. However, whilst playing comes instinctively to all children, without the support of parents, policy makers and the wider community to make play a priority, children will be denied the freedom, spaces and time to themselves to act on their natural instincts.

All games have certain criteria such as a goal, chance, competition, common experiences, equality, freedom and no impact on reality, and depending on the game, people are engaged in some activities, such as thinking, planning, decision-making, concentrating, timing their minds and gaining knowledge. Playing games is a common characteristic of children all over the world. Parents no matter how uneducated they might be, also realise that games and physical exercises are essential for the growth of their children. They try to organise activities pertaining to games within very limited resources. Inability to provide expensive gadgets makes them fall back to traditional games. Parents insist on their children's playing outside home. Though it is not institutionalised, it is customary that evening hours (5 p.m. to 7 p.m.) remain game-hours 
for each child. In hot or cold climate, in open space or crowded parks, in cities or villages, in streets or playgrounds children jump, run, hide, chase each other, and sing and laugh wholeheartedly.

Although children play both indoor and outdoor games, the evening hours are generally meant for outdoor games. However, they play simple but expressive games through which they develop a sense of victory and defeat as well as amplify the traits of leadership. The selection of the game is based on the availability and number of other children, sports equipment and the age-group of the children. They save their pocket money for buying sports items; however, the majority of them cannot afford anything expensive, so most of the items they play with are not very costly. Girls generally play with the items available at home. They prefer to spend their pocket money on coloured ribbons, nail polish, ear tops, etc. Again, there are many games, which do not require any money. Some games require a group of boys and girls whereas others are played either by girls or boys only. Irrespective of the location chosen for playing -school or home or elsewhere- games are designed to provide fun and entertainment. Against this backdrop the study tries to elaborate the different types of traditional games. Further it explores how these traditional games are enriched with the cultural heritage of a society. The research revolves around the socio-cultural significance of these traditional games and thus critically examines the changing scenario of the games played by children in contemporary society as well.

\section{Area of Study and Methods Used}

Traditional children game (folk game) is one of the nation's cultural assets are very important and closely related to psychological functioning of child development. Western Odisha (Kalahandi, Bolangir, Sambalpur, Sonepur, Sundergarh, and Athamallik block of Dhenkanal district) as a culture area different from the rest part of the state geographically, historically, and linguistically; known for its unique and rich cultural heritage. It has distinctive social institutions, festivals, and verbal as well as non-verbal folkloric traditions. Western Odisha has a wonderful exclusive tradition of games, which can be not only played by skilled or sports person, but also every member of family during leisure. Even in the modern age of technology it has more than hundred numbers of games performed by the men, women, and children of all age groups.

The present study is conducted in the Tangarpali village of Attabira Block which comes within Bargarh district. Information was collected from the students of different schools, namely: Tangarpali Primary School, Rujhenmal Primary School, Kantal Primary School and K.P High School. Apart from this, data was also gathered from the teachers as well as the authorities of their respective schools.

Relevant information is gathered with the help of interview schedule. Both participant and non-participant observation methods are employed for data collection. Besides these techniques, case study method is also used to supplement our analysis. Group discussion was also conducted.

\section{Research Results}

As a significant part of culture, traditional games reflect the day today life like preparing food items, collecting firewood, and other food products from forest, selling and buying of agricultural products, different traditional working culture, rites rituals, and festivity of a given social community. There are number of games in Western Odisha which succinctly depict the cultural profile of this area. Like any other artifact, traditional games also have an incredible impact in a given culture. Traditional games are not only for physical strength, it is also a mean for mass entertainment. Impulsive exchange of lore element of given community is also done in between the performance. Performance of traditional games creates bridge of unity between playgroups as well as in society. The players also learn successful application of skill and imitative knowledge from traditional games; and this knowledge is transmitted from one generation to next generation. In this way the traditional games has a great educative value, it is like an educational institution where the performers learns the behaviour, friendship, and cooperation. After all traditional games are a link between past and present of a given society. 'In the street, particularly in the nooks and crannies of public space not under the watchful gaze of adults, children may thus begin forming a public identity and establish their own selfhood and independence' (Spilsbury 2005: 81).

\section{Indigenous Games: Rethinking Childhood}

Given the general difficulty with defining play, and the recognition of its complexity, it is not surprising that there have been numerous attempts to categorise different types of play. However, in the contemporary psychological literature the various kinds of play are generally divided into five broad types based upon the developmental purposes which each serves, partly arising from the evolutionary analyses to which we have referred above, and how each relates to and supports children's learning. These types are commonly 
referred to as physical play, play with objects, symbolic play, pretence/ socio-dramatic play and games with rules. Although each type of play has a main developmental function or focus, arguably all of them support aspects of physical, intellectual and social-emotional growth.

In the 1960s when Mead (1966 cited in Blakely 1994) pointed out that neighbourhoods provide vital opportunities for children to explore their environments without adult direction and learn life lessons about the 'familiar' and the 'strange'. Mathews (2003, cited in Spilsbury 2005) who investigated public space in relation to 9- to 16-year-old children suggested that public space acts as a 'liminal' or in-between setting, in the rite of passage from childhood to adulthood. In fact, evidence suggests that limiting children's freedom in the local area can restrict their opportunities to create social networks and hinder their ability to build strong trusting relationships (Groves 1997 cited in Spilsbury 2005). From all the available evidence, a balance of experience of each of these types of play is likely to be beneficial to children's development. Within this section, the main psychological benefits of each of these types of play and their typical developmental trajectories in physically and psychologically healthy children are described.

\section{A). Physical Play}

This type of play was the earliest to evolve and can be observed in some reptiles and amphibians and most, if not all, mammals (Power, 2000). In human children it includes active exercise play (e.g.: jumping, climbing, dancing, skipping, bike riding and ball play), rough-and-tumble (with friends, siblings or parents/ guardians) and fine-motor practice (e.g.: sewing, colouring, cutting, junk modelling and manipulating action and construction toys). Exercise play begins to emerge during the second year of life and typically occupies around $20 \%$ of children's behaviour by the age of four to five years. The evidence suggests that this type of play is related to children's developing whole body and hand-eye co-ordination, and is important in building strength and endurance (Pellegrini and Smith, 1998). The most extensively researched aspect of physical play, however, is 'rough-and-tumble' play. It includes chasing, grappling, kicking, wrestling and rolling on the ground and appears to have evolved as a mechanism through which children learn to control aggression.

It was quite interesting to note that children play a game that is locally known as "Topa-Topa" (circlecircle). Both boys and girls play this game. The pattern of the game is like that where one player stay in a middle circle and other player stay in the four corners attached to that circle. A maximum number of 9 players can play.The player in the middle has its turn and run around the circle in one leg and other player stand still in the four other circles. While going around the circles the middle player sing different jingle as below:

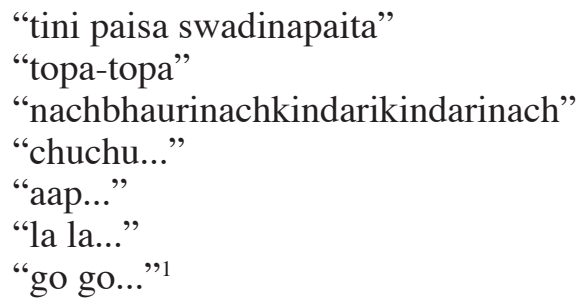

If the middle player touches any other player while going around the circle that player will have the turn. This game signifies the interpersonal relationship between the children in the village.

Kabbadi is another game, which can be played, by both boys and girls in their respective groups. This game is played in two groups. Each group has 7 players. The players try to touch the players of the other group while reciting the jingle like:

"kabadi kabadi bagharabati budha jauchec hunabati"
"band talar tulsi paean dele marsi"
"anda paean dele thanda"2

\footnotetext{
1 [English Transcription]

" 3 coins can give independent thread"

"Topa-Topa" (just a term used during the game)

"dance, crazy girl dance, dance with swirl"

" Chu Chu" (just a term used during the game)

"aap..." (just a term used during the game)

"La La..." (just a term used during the game)

"Go Go..." (just a term used during the game)

2 [English Transcription]
} 
If player of one group tries to touch the players of the other in their house that player is out and if other players touch him/her while not reciting the jingles, than s/he is out. This game helps to inculcate physical and mental control among the participants.

It is observed that both boys and girls play another game called Bisa-amruta (Poison-antidote). This game does not have a fixed number of players. In this game the player having the turn, try to touch other players and other players run away from him/her. While touching the other player, the player having turn has to utter "bisa". After that the player being touched has to sit down and can't run, until another player touches him/her and utters "amruta". If all the players are touched then the first player touched first has the turn and the game continues.

Yet, another game is exclusively played by girls, known as "Rassi-degani" (Rope Jumping). This game may either have multiple players or it can be played alone as well. The players use a skipping rope. The player has to jump the rope once as the skipping rope runs round her body. She has to continue the process. The player is found to be disqualified either if she stops or if she wrongly crossed by the rope. This game socializes the girls to a restricted geographical boundary as she plays it in the closest periphery of her house.

\section{B). Play with Objects}

This second type of play is also widely observed in primates (Power, 2000) and in humans concerns children's developing explorations, as young scientists, of the physical world and the objects they find within it. Play with objects begins as soon as infants can grasp and hold on to them; early investigative behaviours include mouthing/biting, rotating while looking, rubbing/stroking, hitting and dropping. This might be described as 'sensory-motor' play when the child is exploring how objects and materials feel and behave. From around eighteen to twenty four months toddlers begin to arrange objects, which gradually develop into sorting and classifying activities. By the age of four years, building, making and constructing behaviours emerge. As with all other types of play, play with objects often also incorporates other types of play, as it clearly has physical and manipulative aspects and often, in children, is carried out within a pretence or socio-dramatic context. It is a relatively well-researched type of play, as it is distinctively related to the development of thinking, reasoning and problem-solving skills. When playing with objects, children set themselves goals and challenges, monitor their progress towards them, and develop an increasing repertoire of cognitive and physical skills and strategies.

The children in the village were noticed playing a traditional game called as "PatarAnati" (Bringing the right leaf). This game is played by both boys and girls. All the players are divided into two circles, one where the players having the turn stay and other where rest of the players wait.The players on the other side ask the single player as "kiskiskiskapatar"(Whose, whose, which leaf). The player having the turn utters the name of a particular leaf available nearby and rest of the players move outside to collect that leaf. All players try to gather inside another circle carrying the leaf and the player having turn tries to touch them. If $\mathrm{s} / \mathrm{he}$ is able to touch them then the turn shifts to that player and if not the turn continues with the same player. If all players enter the circle with that particular leaf, they say "itlitilotilokainpatar milo"(Which leaf do you find?).This game trains the children to strengthen the peer group relation.

Yet another game called "Gutka" (Pebble Game) is exclusively played by the girls only. In this game approximately 5 to 10 round small pebbles are used by the players. While playing with the 5 or 10 pebbles which ever may be, player spreads all of them on the floor and picks one pebble. Then the player throws one pebble and tries to pick another pebble while the other one is in the air and then catches both of them together. Likewise she picks all the pebbles one by one. Just like picking one pebble again the player follows the same process and picks two pebbles at a time and it continue till she picks all the ten at once. This round is played for 10 times and if meanwhile any player fails to pick the pebble or the pebble falls down and she cannot catch it or she touches the unrequired pebbles she will be disqualified and the turn goes to the next players. Usually 3-4 players play this game at a time. This game is played inside the home or in the veranda. This shows that adolescent girls' learns and practices to restrict her mobility within the house.

\section{C). Symbolic Play}

Play with language starts very early in life with children under the age of one-year-old playing with sounds, and, as they grow older, particularly playing with the sounds of the language or languages they are hearing around them. This play is a very active process and quickly develops into making up new words, playing with rhymes, and eventually young children's love of puns and other jokes with language. Exten-

\footnotetext{
"Kabadi (just a term used during the game) the old man is going to grind powder"

"he throw us the water near the tulsi plant of the pond"

"and the water is cold"
} 
sive research has clearly established that this type of play is a powerful support for developing language abilities and, crucially, through its support for phonological awareness, impacts upon the ease with which young children develop early literacy skills (Christie and Roskos, 2006).

Studies of children's drawings have demonstrated how through drawing, children gradually increase their 'graphic vocabularies', and their ability to organise graphic elements into a pictorial representation (a kind of 'graphic grammar'), becoming increasingly able to use this mode of symbolic representation to express their meanings (Jolley, 2010; Ring, 2010). The evidence from these studies suggests that children's visual literacy (i.e. their ability to understand pictures, photographs, diagrams, scale models, plans, maps etc) is importantly enhanced by their experiences of playing with a variety of visual media. Musical play is another very under-researched area, despite being a ubiquitous and highly significant form of play in all human cultures. From a very early age, children sing, dance and delight in exploring and making sounds of all kinds, with their own bodies and with all kinds of objects.

It is observed that a game named "Lukati" (Hide and seek) was played as a symbolic play by the children in the village. Both boys and girls play this game. There is no fixed number of players in this game. In this game the player, which has the turn, closes his/her eyes and counts numbers for a while till a particular number, while other players hide themselves in different places. After completing to count the player tries to find other players. When s/he searches and then finds the first person he says " 1 st trip". Then when he searches and finds the second person he says " $2^{\text {nd }}$ trip" and so on. He repeats and continues the same process. After he finds all the other players then the first player found, has his turn and starts searching. In case a player is searched and not found then his turn of searching will not come. The children in this game do not require any play equipments or objects to play with, rather play it bearing a symbolic role which reflects their traditional skill.

Both boys and girls play a game named "Lanthanchor"(Lamp Thief). There is no fixed number of players in this game. The player having the turn stands in front of all players facing backward and says "lanthanchor". Other players have to constantly stand within their fixed boundary where they should neither move nor even talk to each other. If the player having his/her turn finds anyone moving then s/he calls his/her name. Then it becomes the turn of the player whose name is uttered. Likewise the game continues. This game helps the children to organise activities pertaining to games within very limited resources.

\section{D). Pretence/Socio-dramatic Play}

High-quality pretend play has repeatedly been shown to be very closely associated with the development of cognitive, social and academic abilities. Studies have reported the impact of play world experience on narrative skills in five to seven year olds (Whitebread and Jameson, 2010), of pretence play on deductive reasoning and social competence, and of socio-dramatic play on improved 'self-regulation' among young children who are prone to be highly impulsive. A range of studies have supported Vygotsky's (1978) insights concerning the impact of this type of play on children's representational and self-regulatory abilities (Karpov, 2005). This is also a type of play in which a high prevalence of 'private speech' is commonly observed (Berk, Mann and Ogan, 2006).During socio-dramatic play, in particular, children are obliged to follow the social rules governing the character they are portraying. Berk and colleagues, 2006 report a number of studies with three and four year olds demonstrating a clear link between the complexity of socio-dramatic play and improvement in social responsibility. However, the research evidence suggests that these concerns are misplaced and that attempts by adults to discourage or forbid them are generally counter-productive. Gun play, similar to rough-and-tumble, is easily distinguishable from real aggression or violence. In this kind of play, as in all other aspects of socio-dramatic play, children are developing their co-operative and social skills in contexts which are salient to their interests, and which arise from their real and vicarious experiences (Holland, 2003; Levin, 2006).

A typical type of play named "Kachi-kudi" (Utensils and Cooking) was observed. Girl children of a smaller age group specifically play this game. These girls use small utensils and pretend to be working in a kitchen. In this game sand is used as rice, leaves as money, and grass as vegetables. It is a kind of make a believe game where girls used to play in the kitchen as well as in their verandas and courtyards. They pretend that they are very busy in cooking and also doing other household works. This game reflects the cultural construction of girlhood. It is a way of life adopted by the adolescent girls for their future.

Another game that is played is called "Chel-chelia- Bhai" (Farmer Brother). Both the boys and girls play this game. There is no fixed number of the players in this game. In this game all the players stand in a circle while holding the hands of each other. At the end of the circle there is a leader who leads the game forward. While playing the game following jingle is recited by the players: 


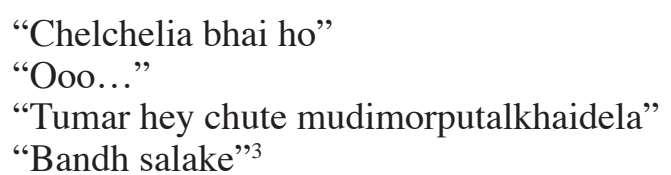

Then one player selected by other players is tied. Gradually all the players are tied. The leader then strikes at the back of the tied players. Then two leaders hold the tied players by the thumb of their feet and hands and swing them. If the leader leaves the thumb and hand, then s/he is named as "ghasian" (untouchable). Then the "ghasian" tries to touch all the other players who start to run away from him/her. If s/he is successful in touching all the other players, they are also called as "ghasian". When all the players become "ghasian", the game is over. This game denotes the segmental division in our society, wherein the children are brought up with a feeling of social differentiation. It is quite interesting to note a game by the name "Bagh-cheli" (Tiger-Goat) is played by both girls and boys.

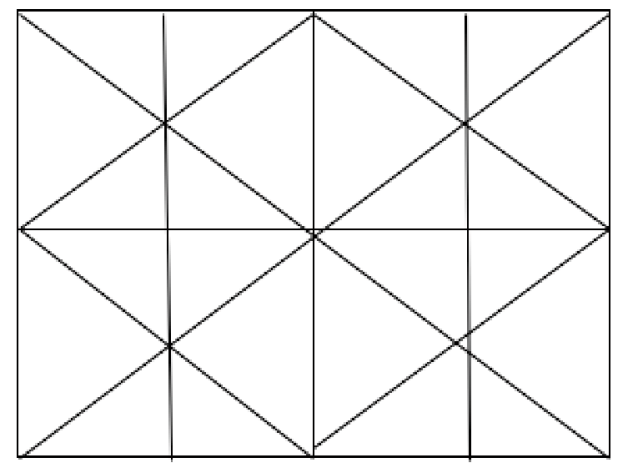

This game has many numbers of players, where 4 are "bagh" and 18 are "cheli". Here different shapes of stone are used as dice. Here the player chooses "bagh" and places the dice at the four corners of the board. The other players choose "cheli" and place the dice in between "bagh". Then "bagh" tries to kill the "cheli" and moves ahead. In order to rescue the "cheli" another dice is moved ahead to surround "bagh". If "cheli" dice will surround all the "bagh" dice, then the game is over. In case the "bagh" dice kills all the "cheli" dice, the game will be over. But if "cheli" dice surrounds the "bagh" dice and the next house is empty then "bagh" can kill the "cheli" by jumping over it and move to the empty house. This indoor games helps the children to develop their cognitive skills and thereby refines their ability to understand and judge.

The girls in the village play another game known as "Budhima-budhima" (Grand ma Grand Ma). In this game all the player stands in circle while holding each other's hand and one player stand in the centre of the circle. Then they ask few questions to the player in the centre saying "budhima" and the player answers to that question. The questions are asked in the form of jingles, like:

Q. "Budhima budhima kahi jaucha?"

A. "gadhi"

Q. "suna muda pakei dele badheijiba"

A. "ebua, band sarluche"

"ebua, guhurita"

"ebua, eta bhalta"

Q. "budhima kanabatucha?"

A. "haldi"

Q. "amku tike makheidiya?"

Q. "tumarnam kana?"

A. players say different fruits name ${ }^{4}$

3 [English Transcription]

"O my farmer brother"

"Yes"

"Your animal is eating vegetables from my garden"

"Tie that animal"

4 [English Transcription]:

"Oh Old lady, where are you going?" 
Meanwhile, if the player in the centre says "khadiya bhoota", all the other players run away and the game is over. The girls playing this game are groomed towards acquiring the attributes of womanhood.

\section{E). Games with Rules}

Young children are strongly motivated to make sense of their world and, as part of this; they are very interested in rules. As a consequence, from a very young age, they enjoy games with rules, and frequently invent their own. Opie and Opie's (1959) collections of children games and folklore are a testament to children's love of games with rules. The use of electronic and computer games by today's children is another particular area of anxiety for parents and teachers. The concerns here relate to violence and to the addictive nature of some games. However, the evidence in this area is equivocal. A game played by both the boys and the girls is called as "Pahadi/Golgol" (Circle-Circle).

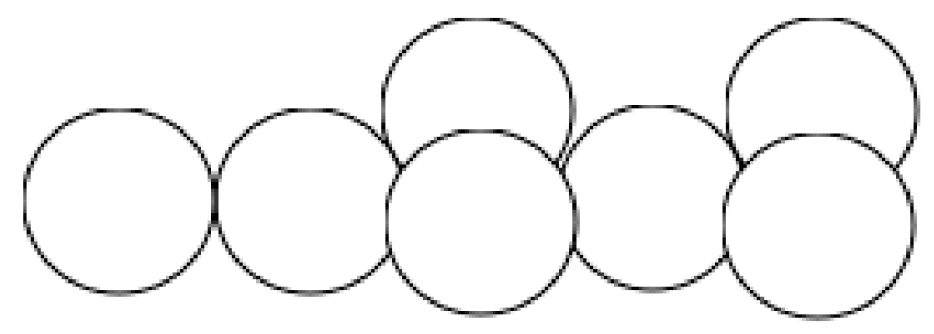

A team of 3 to 4 players play this game at a time. Each player plays with one dice (khapri) and the ground is divided into 7 circles called as house. During this game the player throws the dice in the first house and jumps over the dice in one leg. Then s/he takes the dice in the hand and jumps into the next house. In the first, second and fifth house the player jumps with one leg and in the third, fourth, sixth and seventh house they reside as pairs, the player jumps there in two legs. When the players reach the sixth and the seventh house s/he throws the dice outside and jumps on it. Incase the players miss the dice s/he has to leave his/her turn for the next player and again s/he can start over from where it left in the next turn. After finishing the cycle from one house the player then throws the dice to the next house and so on. If the dice falls on the lines or touches the line then also s/he has to leave his/her turn. The children playing these games follow a self made rule that enhances their personality. It channelizes their way of life to be more systematic. Another game is also played by both the boys and the girls known as "Kit-kit" (Term-Term).

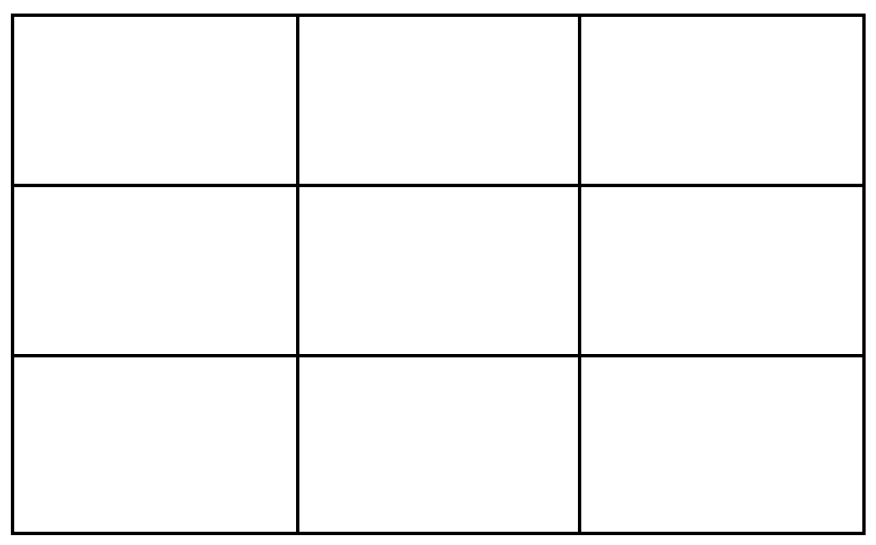

"to bath"

"You might find gold in there"

"Oh, the pond side is slippery"

"Oh, this is not gold"

"Oh, this is found to be good"

"Oh Old lady, what are you grinding?"

"Turmeric"

"Can we take some?"

"What is your name?" 
In this game each player has a dice (khapri). Four to five players play this game and one at a time. The total area of this game is divided into 9 squares where the player jumps from one square to another in clockwise direction with one leg while chanting "kit-kit". During this game the player throws the dice in the first house and jumps over the dice with one leg. Then s/he slides the dice outside the total area by his leg and jumps into the next house and continues in this way till the middle house. When the player reaches the middle house s/he can then use his/her both legs and then jump over the dice outside the main area. Likewise the player has to finish all the nine houses. After reaching the $9^{\text {th }}$ housein the final round, the player can throw the dice without seeing to any one of the house and which will be considered as his/her house. The player can put a ' $\mathrm{X}$ ' sign on that house so that no other player can put their foot on that. If any player disqualifies the game rule, the next player takes his/her turn.

"Thin-thin-phat" (Thief and Handkerchief) is a game played by both the boys and girls. There is no limitation on number of players. In this game all the players sit on the ground in circle with closed eyes. One of the players who has the turn takes a handkerchief or a piece of cloth in his hands and starts running outside the circle. After completing few rounds of the circle the player keeps the handkerchief or piece of cloth behind another player who is sitting and then hits him/her on the back and then runs round the circle again. The player who was hit at his/her back hit picks up the cloth kept at his/her back and starts running behind the player. If the first player sits at the place of second player, then the second has the turn to run round the circle. The game does not have any time limit and thus it continues. This games reflects the creativity of children where they try to play simple but expressive games through which they develop a sense of victory and defeat as well as amplify the traits of leadership.

\section{Significance of Traditional Games: A Changing Scenario}

Traditional games always play a significant role in culture as they reflect the normal errands of day to day life like preparing food items, collecting firewood, and other food products from forest, selling and buying of agricultural products, different traditional working culture, rites rituals, and festivity of a given social community. The cultural profile of Western part of Odisha has also been depicted by its various traditional games, which are unlike the popular western games neither organized nor own any kind of complexities. These games have a great legroom for portrayal of day-to-day activities. The game Paen Anba (bringing water) that is carried out by both boys and girls of five to eight years age group through which the cooking tradition of Western Odisha is visualized. Participants are taking water from pond or river and prepare different traditional food items symbolically. They use different leaves and stems for preparing these food items.

Some games also have their origin in ancient literatures of India. Popular Mankada-Kumbhira (monkeycrocodile) game has emanated from the ancient Sanskrit text Panchatantra. In addition to this, players of traditional games also sing various lovely short poems and Dhaga Dhamali during every stage of the games to make it more lively and aesthetic. Performance of traditional games as 'event' creates a significant space for exchange of lore element. The traditional knowledge about games, as well as cultural knowledge of a given society have been exchanged between participants, and handed down generation to generation. Players of traditional games get a familiar idea about their environment, house patterns, agricultural practices, food habits, and culinary tradition through this game performance. And this knowledge exchanged with one individual to other in the context of enactment. Performance of traditional games creates a strong sense of unity and mutual understanding between the players in a given community. The playgroups though they are not fixed, meet frequently, performed the games, and being united after the performance also. This unity is not just a playgroup's unity, it continues for lifelong, which helps them for leading a peaceful social life in future.

Participants of traditional games of Western Odisha learn socialization, friendship, co-operation, unity, discipline, and different social rule regulations from the performance of games. In traditional games players are actively constructing knowledge through their experiences of games, they actively learn about the game world -the entire system of interaction. Players come to a game with prior knowledge and experience about the real and game world, about games they have played before and so on. They then attempt to apply this knowledge to the new situation, provided by the game. Players construct mental pictures, or models, in their head based on the patterns they discover during play. Through performance of games, players build up a mental model, or image, of the game system and how it plays; in essence how it works. They can then use these models to predict what would happen, experiment to find out what actually did happen, and got reflected on the outcome.

In Ghar Banaba game when they demand dowry for their son's marriage, they are asking for television, disk player, motorbike and other modern gadgets, which never took place before. It is quite interesting to note that when they are playing Bag-chhel, or Dhadi-ki-Dhukdi in hot afternoon of summer season they challenge other party by saying, "I will definitely defeat you, would you give me a cold drink?" or "If you 
are defeated, you have to give me a cold drink!" Punishment and fine for defeated group or player is a part of traditional game performance, but the cold drink as fine is certainly due to the influence of modern culture.

As culture is dynamic, culture changes; people discard, modify, retain in a proportion of changing social scenario. The members at a given time cannot by themselves define the boundaries of social experience. So long as new generations are being born into society, social context will remain a dynamic process not a static setting. In a dynamic socio-cultural scenario the artifact indecisively adopt all the influence comes its way. The traditional games of Western Odisha also adopted many things in changing context.

One can trace the traditional nuptial activities from the games Mudilukenas well as see the influence of modernization, as the participants are using the cold drink caps as equipment for the games Ghacha, and Pati. Changing socio-cultural scenario has created a good space for developing new games for the players of traditional games in Western Odisha. Like ChorPulish, RajaMantri, they have created a game 'Sarapanch', experiencing the three tiers Panchayati raj system. They have added other characters like Chairman, B.D. $O$., and Member (ward member) to this game also. They have also developed string play KhatPinjra (cot and birdcage) as they have seen it in television. They quickly design cot, net, basket, tree, peacock, and birdcage by operating string. The prevailing cut throat competition in educational sectors is adding salt to the injury. Time devoted to the studies has increased manifold in recent years. Games are being played only to earn certificates, which will in turn get the players some jobs. Astoundingly wide varieties of traditional games show the beauty of the creative mind.

\section{Concluding Remarks}

Play is a fundamental human right for all children, regardless of age, gender, culture, social class or disability. As Lester and Russell conclude:

'We must exercise caution and not make it too much an object of adult gaze. Children's play belongs to children; adults should tread lightly when considering their responsibilities in this regard, being careful not to colonise or destroy children's own places for play through insensitive planning or the pursuit of other adult agendas, or through creating places and programmes that segregate children and their play'.

'Adults should be aware of the importance of play and take action to promote and protect the conditions that support it. The guiding principle is that any intervention to promote play acknowledges its characteristics and allows sufficient flexibility, unpredictability and security for children to play freely.' (Lester and Russell 2010: 46)

Children play because they want to-and it is the process of playing that counts. The rules come from the children themselves. Play is rich in symbol and metaphor, helping children to figure out the affective world as well as the physical and social worlds. Through play, children learn about themselves and who they are in relation to others. Children differ in many ways. While play can bridge those differences, it can also emphasize them. Boys' and girls' play, for example, has similarities and glaring differences that challenge the teacher to extend children's horizons as they acknowledge their preferences. Play can be a "social bridge" among children from different cultures, since all children play. Culture influences both how children approach play and how their adults see play.

There are many games lost due to lack of proper promotion, even older people also not able to recall that exactly. According to Edgardo Civallero (2006), "a people's intangible heritage is composed by the non-material part of its culture: tales and narratives, games and songs, music and all the knowledge usually transmitted by oral or sound means, in traditional societies as well as in urban westernized ones". Considering traditional games as a significant part of the cultural heritage, they should be documented, protected, revitalized, and promoted. Traditional games have important values towards the overall development of the individual human being and one's community. Traditional games do not demand any substantial material and financial resources or investments, but they can contribute to better inter-cultural understanding and mutual tolerance, both within and among the communities of nation, which will contribute to build a culture of peace. Not in Western Odisha in all over the world, the traditional games contribute mutual understanding and peaceful behaviour to a life of different cultural and social groups, communities and nations. They are means of their identity. A world that understands and supports children's play is a world that is likely to be healthier, more vital, more alive and happier than a world without play. Therefore the significance of traditional games and identity must be strengthened and the opportunities for practicing them must be held open for all human beings. 


\section{References}

Berk, L. E., Mann, T. D., and Ogan, A. T. (2006). Make-Believe Play: Wellspring for Development of SelfRegulation. In D.G. Singer, R.M. Golinkoff and K. Hirsh-Pasek (Eds.), Play=Learning: How Play Motivates and Enhances Children's Cognitive and Social-Emotional Growth. (pp. 74-100). Oxford: Oxford University Press

Civallero, Edgardo (2006). Traditional Games, Music and Oral Tradition: Intangible Tools in Multicultural Libraries.

Christie, J.F. and Roskos, K.A. (2006).Standards, Science, and the Role of Play in Early Literacy Education. In D.G. Singer, R.M. Golinkoff and K. Hirsh-Pasek (Eds) Play = Learning. Oxford: Oxford University Press.

Cunningham, H. (2005). Children and childhood in western society since 1500.Pearson Education.

Elkind, D (2008) 'The power of play: Learning what comes naturally', American Journal of Play, 1, 1, Summer, 1-6.

Gaskins, S., Haight, W. and Lancy, D. F. (2007). The Cultural Construction of Play. In A. Göncü and S. Gaskins (eds) Play and Development: Evolutionary, Socio-cultural and Functional Perspectives. Mahwah, NJ: Lawrence Erlbaum

Ginsburg, K (2007) 'The importance of play in promoting healthy child development and maintaining strong parent-child bonds', Paediatrics, 119, 182-191, in BTHA (2011) Active Play and Healthy Development. Available online at: http://www.btha.co.uk/consumers/template.php?id=169 (Accessed Nov. 2011).

Groves, BM (1997) 'Growing up in a violent world: The impact of family and community violence on young children and their families', Topics in Early Childhood Special Education, 17, 1, 74-102, in Spilsbury, J C (2005) 'We Don't Really Get to Go Out in the Front Yard': Children's home range and neighbourhood violence', Children's Geographies, 3, 1, 79-99.

Holland, P. (2003). We don't play with guns here. Open University Press.

Jolley, R. P. (2010). Children and Pictures.Chichester, UK: Wiley-Blackwell.

Karpov, Y. V. (2005). The Neo-Vygotskian Approach to Child Development. Cambridge: Cambridge University Press.

Lester, S and Russell, W (2010) Children's right to play: An examination of the importance of play in the lives of children worldwide. Working Paper No. 57, The Hague, The Netherland: Bernard van Leer Foundation.

Levin, D. E. (2006). Play and violence: Understanding and responding effectively. In D.P. Fromberg and D. Bergen (Eds.).Play From Birth to Twelve. Context, Perspectives, and Meanings, 2nd Ed. (pp. 395404). London: Routledge.

Matthews, M. H. (2003) The street as a luminal space, in: Christensen, P., and O'Brien, M (eds) Children in the City. London: RoutledgeFalmer, 101-117, in Spilsbury, J C (2005) 'We Don't Really Get to Go Out in the Front Yard': Children's home range and neighbourhood violence', Children's Geographies, 3, 1, 79-99.

Mead, M (1966) 'Neighbourhood and human needs', Ekistics, 21, 124-126, in Blakely, K S (1994) 'Parents' Conceptions of Social Danger to Children in the Urban Environment', Children's Environment, 1, $1,16-25$.

Opie, I.A. and Opie, P (1959).The Lore and Language of Schoolchildren.Clarendon Press.

Pellegrini,A.D, and Smith, P.K. (1998). Physical Activity Play: The Nature and Function of a Neglected Aspect of Play. Child Development, 69(3).577-598.

Playwork Principles Scrutiny Group (2005) Playwork Principles. Play Wales, Cardiff. Available online at: http://www.skillsactive.com/playwork/principles (Accessed Nov. 2011).

Power, T. G. (2000).Play and Exploration in Children and Animals. Mahwah, NJ: Lawrence Erlbaum.

Ring, K. (2010). Supporting a playful approach to drawing. In P. Broadhead, J. Howard and E. Wood (Eds.).Play and learning in the early years. London: Sage.

Spilsbury, J. C. (2005) 'We Don't Really Get to Go Out in the Front Yard': Children's home range and neighbourhood violence', Children's Geographies, 3, 1, 79-99.

Vygotsky, L. S. (1978). The Role of Play in Development. In Mind in Society. (pp. 92-104). Cambridge, MA: Harvard University Press. 